\title{
DOES COMORBID OBESITY OR CHRONIC PANCREATITIS INFLUENCE THE CHOICE AND EFFECTIVENESS OF GLUCOSE-LOWERING THERAPY IN TYPE 2 DIABETIC PATIENTS?
}

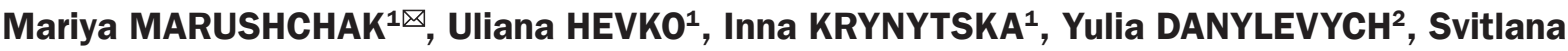 \\ DANCHAK $^{2}$, Lyudmyla MAZUR ${ }^{2}$
}

${ }^{1}$ Department of Functional and Laboratory Diagnoses, I. Horbachevsky Ternopil National Medical University, Ternopil, Ukraine

${ }^{2}$ Department of Clinical Immunology, Allergology and General Patient Care, I. Horbachevsky Ternopil National Medical University, Ukraine

Received 19 Jan 2021, Accepted 24 Febr 2021

https://doi.org/10.31688/ABMU.2021.56.1.03

\begin{abstract}
Introduction. The complexity of the interaction between type 2 diabetes mellitus (T2DM), comorbidities, and emerging complications requires a clinical approach that manages risk while maintaining indicated therapeutic goals.

The objective of the study was to analyse the frequency and effectiveness of mono- and combined glucose-lowering therapy in T2DM patients with obesity and chronic pancreatitis (CP).

Material and methods. The retrospective study analysed 579 medical records of T2DM patients, who were divided in the following groups: group 1-patients with normal body weight and without CP $(n=67)$; group 2 - patients with normal body weight and with $\mathrm{CP}(\mathrm{n}=32)$; group 3- overweight patients without CP $(\mathrm{n}=126)$; group 4 - overweight patients with $\mathrm{CP}(\mathrm{n}=33)$; group 5 - obese patients without CP $(n=262)$; group 6 - obese patients with CP $(n=59)$. When evaluating
\end{abstract}

\section{RÉSUMÉ}

Obésité comorbide ou pancréatite chronique, influencent-t-elles le choix et l'efficacité de la thérapie de réduction du glucose chez les patients avec diabète de type 2?

Introduction. La complexité de l'interaction entre le diabète sucré de type 2 (DT2), les comorbidités et les complications émergentes nécessite une approche clinique qui gère le risque tout en maintenant les objectifs thérapeutiques indiqués.

L'objectif de l'étude. Le but de cette étude était d'analyser la fréquence et l'efficacité des traitements hypoglycémiants mono- et combinés chez les patients diabétiques de type 2 souffrant d'obésité et de pancréatite chronique (PC).

Matériel et méthodes. L'étude rétrospective a analysé 579 dossiers médicaux des patients atteints de DT2: groupe 1 - patients de poids corporel normal et sans 
the effectiveness of the received therapy, the target value of $\mathrm{HbA1c}$ less than $7 \%$ was considered.

Results. Most of the patients with $\mathrm{T} 2 \mathrm{DM}+\mathrm{CP}$ and T2DM with normal body weight received combined therapy. The presence of CP significantly influences the choice of treatment for T2DM, particularly, $81.5 \%$ of patients with T2DM and CP were prescribed combined therapy. There was no significant difference between serum glucose and $\mathrm{HbAlc}$ levels in patients with only T2DM and comorbid T2DM+CP+overweight/ obesity regarding monotherapy vs combined glucose-lowering therapy. However, glucose and $\mathrm{HbAlc}$ levels in patients with only T2DM on monotherapy were significantly lower, respectively, by $41.72 \%$ and $25.64 \%$ vs patients with comorbid CP and overweight/ obesity, who were also prescribed monotherapy.

Conclusion. The presence of CP significantly influences the choice of treatment for T2DM, while overweight/obesity is not a criterion for choosing mono- or combined glucose-lowering therapy. The use of metformin as monotherapy and the use of combined therapy in most of patients with only T2DM and comorbid T2DM do not achieve the target levels of glucose and HbA1c.

Keywords: type 2 diabetes mellitus, obesity, chronic pancreatitis, glucose-lowering therapy, effectiveness.

\section{List of abbreviations:}

CP - chronic pancreatitis

T2DM - type 2 diabetes mellitus

FFAs - free fatty acids

ApoB - apolipoprotein B

$\mathrm{TG}$ - triacylglyceroles

VLDL-C - very low-density lipoprotein cholesterol

HDL-C - high-density lipoprotein cholesterol

BMI - body mass index

ALT - alanine aminotransferase

AST - aspartate aminotransferase

ADA-American Diabetes Association

\section{INTRODUCTION}

Diabetes mellitus (DM) has become a serious social problem because of its global spread ${ }^{1}$. According to the International Diabetes Federation data, in 2019 there were 463 million people in the world diagnosed with DM, 91\% of whom suffered from type 2 diabetes mellitus (T2DM); it is assumed that the number of DM people will reach 700 million by $2045^{2}$. Healthcare outcomes associated with DM, related expenses and treatment options are complicated by its comorbidities ${ }^{3}$. The well-known comorbidities associated with DM are obesity and dyslipidemia ${ }^{4,5}$.
$\mathrm{PC}(\mathrm{n}=67)$; groupe 2 - patients avec un poids corporel normal et avec $\mathrm{PC}(\mathrm{n}=32)$; groupe 3 - patients en surpoids sans $\mathrm{PC}(\mathrm{n}=126)$; groupe 4 - patients en surpoids atteints de $\mathrm{PC}(\mathrm{n}=33)$; groupe 5 - patients obèses sans $P C(n=262)$; groupe 6 - patients obèses avec $P C(n=59)$. Lors de l'évaluation de l'efficacité du traitement reçu, la valeur cible d'HbA1c inférieure à 7\% a été prise en compte.

Résultats. La grande majorité des patients atteints de DT2 + CP et de DT2 avec un poids corporel normal ont reçu un traitement combiné. La présence de $\mathrm{CP}$ affecte significativement le choix du traitement pour le DT2, en particulier, $81,5 \%$ des patients atteints de DT2 et de CP ont reçu une thérapie combinée. Il n'y avait pas de différence significative entre les taux de glucose et d'HbAlc chez les patients atteints uniquement de DT2 et de DT2 comorbide avec CP et de surpoids/ obésité en monothérapie par rapport à un traitement hypoglycémiant combiné. Cependant, les taux de glucose et d'HbAlc chez les patients atteints de DT2 uniquement en monothérapie étaient significativement inférieurs, respectivement, de $41,72 \%$ et 25,64\% par rapport aux patients atteints de CP comorbide et de surpoids / obésité, qui ont également été prescrits en monothérapie.

Conclusion. La présence de CP affecte significativement le choix du traitement pour le DT2, tandis que le surpoids / obésité n'est pas un critère pour choisir un traitement hypoglycémiant mono- ou combiné. L'utilisation de la metformine en monothérapie et l'utilisation d'un traitement combiné chez la grande majorité des patients atteints uniquement de DT2 et de DT2 comorbide n'atteignent pas les taux cibles de glucose et d'HbAlc.

Mots-clés: diabète sucré de type 2, obésité, pancréatite chronique, traitement hypoglycémiant, efficacité.

Excessive abdominal fat, deregulation of adipose tissue and inflammation that is characterized by the secretion of diabetogenic adipokine pattern, which contributes to the disruption of insulin action in skeletal muscle, brain, liver, and other organs are factors that connect obesity and dyslipidemia to T2DM' . Simultaneously, free fatty acids (FFAs) release is increased by insulin-resistant fat cells; high FFAs levels contribute to the production of triacylglyceroles (TG), which in turn stimulates the secretion of apolipoprotein B (ApoB) and very low-density lipoprotein cholesterol (VLDL-C) ${ }^{7}$. Hyperinsulinemia, in addition to high ApoB and VLDL-C, is associated with low 
high-density lipoprotein cholesterol (HDL-C) levels ${ }^{8}$. Hyperglycemia also adversely affects lipoproteins (particularly LDL and VLDL) due to increased glycosylation and oxidation, reduces vascular compliance and promotes the development of aggressive atherosclerosis ${ }^{9}$. There is evidence to suggest that insulin also has a direct atherogenic effect on the vascular wall, and the production of LDL-C and TG is stimulated by hyperinsulinemia ${ }^{10}$.

There are other diseases, in addition to well-known comorbidities linked to DM, associated with obesity, insulin resistance (IR), dyslipidemia and T2DM, including chronic pancreatitis (CP). Exocrine insufficiency of the pancreas, determined by the fecal pancreatic elastase-1 levels, was observed in 53.3\% of all examined T2DM patients ${ }^{11}$. The development and progression of both CP and T2DM have common pathogenic factors, that is being the reason why these disorders can cause and exacerbate each other. It is noteworthy, that DM patients have about twice the risk of developing pancreatitis, and, conversely, about a third of patients with acute pancreatitis develop pre-diabetes and/or $\mathrm{DM}^{12}$.

A wide range of therapies is available for the treatment of T2DM patients, and each class has advantages and disadvantages based on their mechanisms of action and clinical experience. The complexity of interaction between T2DM, comorbidities, and emerging complications requires a clinical approach that manages risk while maintaining indicated therapeutic goals ${ }^{13}$. The current methods of T2DM treatment are oral insulin secretagogues, sulfonylureas, repaglinide, nateglinide, biguanides, thiazolidinediones, alpha-glucosidase inhibitors, pramlintide and exenatide ${ }^{14}$. The first choice for the treatment of T2DM, based on its well-defined efficacy, safety profile, low-cost and potential to reduce the risk of cardiovascular events is metformin ${ }^{15}$, which inhibits hepatic glucose production and improves insulin sensitivity ${ }^{11}$. Insulin also can be used as hypoglycemic agent T2DM patients. If an initial glycated hemoglobin (HbA1c) level exceeds 9\%, or if diabetes is uncontrolled despite optimal oral glycemic therapy, insulin therapy is recommended for T2DM patients $^{16,17}$.

The objective OF THE Study was to analyse the frequency of mono- and combined glucose-lowering therapy assignment in T2DM patients with obesity and chronic pancreatitis and to assess the role of comorbidities in the choice of corrective therapy and its effectiveness.

\section{Materials AND MEthods}

The retrospective study analysed 579 medical records of patients with T2DM hospitalized in the Endocrinology department of Ternopil University Hospital in 2018-2019, who were divided in the following groups: group 1- patients with normal body weight and without CP $(n=67)$; group 2 - patients with normal body weight and with CP $(\mathrm{n}=32)$; group 3 - overweight patients without $\mathrm{CP}(\mathrm{n}=126)$; group 4 overweight patients with $\mathrm{CP}(\mathrm{n}=33)$; group 5 - obese patients without $\mathrm{CP}(\mathrm{n}=262)$; group 6 - obese patients with $\mathrm{CP}(\mathrm{n}=59)$.

The ethical principles included in the Declaration of Human Rights adopted in Helsinki, in 1975, and revised in 2008, were fully respected in our study. The enrolled subjects participated in this study voluntarily, completed and signed a written informed consent. The study protocol was approved by the Ethics Committee of I. Horbachevsky Ternopil National Medical University, Ukraine.

The distribution of patients into the study groups is presented in Table 1. There was no significant difference in age and gender between the study groups.

Verification of T2DM was performed in accordance with the recommendations of the American Diabetes Association (ADA) (2019) ${ }^{14}$. The criteria for T2DM diagnosis were based on the value of HbA1c $(\geq 6.5 \%)$, which was determined using an automatic biochemical analyzer COBAS 6000 (Roche Hitachi,

Table 1. Study groups $(\mathrm{n}=579)$

\begin{tabular}{cccc}
\hline Group & Patients cohort & $n$ & $\%(95 \%$ CI $)$ \\
\hline 1 & T2DM patients with normal body weight and without CP & 67 & $11.57(8.97 ; 14.70)$ \\
\hline 2 & T2DM patients with normal body weight and with CP & 32 & $5.53(3.78 ; 78.02)$ \\
\hline 3 & Overweight T2DM patients without CP & 126 & $21.76(18.13 ; 25.91)$ \\
\hline 4 & Overweight T2DM patients with CP & 33 & $5.70(3.92 ; 8.00)$ \\
\hline 5 & Obese T2DM patients without CP & 262 & $45.25(39.94 ; 51.07)$ \\
\hline 6 & Obese T2DM patients with CP & 59 & $10.19(7.76 ; 13.14)$ \\
\hline
\end{tabular}


Germany) and glucose concentration, which was determined using a standard set on an automatic biochemical analyzer BAS INTEGRA® 400 (Roche Diagnostics).

Verification of $\mathrm{CP}$ was based on the recommendations of the American Pancreatic Association ${ }^{18}$.

The body mass index (BMI) was calculated by the formula: body weight $(\mathrm{kg}) /$ height $\left(\mathrm{m}^{2}\right)$. Data were interpreted according to WHO recommendations: normal weight in the range of $20.0-24.9 \mathrm{~kg} / \mathrm{m}^{2}$; overweight (pre-obesity) 25.0-29.9 kg/m² ; class 1 obesity $30.0-34.9 \mathrm{~kg} / \mathrm{m}^{2}$; class 2 obesity $35.0-39.9 \mathrm{~kg} / \mathrm{m}^{2}$ and class 3 obesity $>40 \mathrm{~kg} / \mathrm{m}^{2}$.

Inclusion criteria: clinical, laboratory and instrumental signs of T2DM, CP and obesity, no sharp increase (not more than 3 times from the upper limit of normal) in the activity of alpha-amylase, lipase, alanine aminotransferase (ALT), transaminase (AST), alkaline phosphatase and gamma-glutamyltranspeptidase in blood serum.

Exclusion criteria from the study: signs of clinically significant neurological, mental, renal, hepatic, immunological, gastrointestinal, urogenital disorders, lesions of the musculoskeletal system, skin, sense organs, endocrine system (except T2DM) or hematological diseases that are uncontrolled, acute pancreatitis, unstable or life-threatening heart disease, patients with malignant neoplasms who have not been in complete remission for at least 5 years, medication (drug) dependence, alcohol addiction.

Metformin is the first-line medication in the treatment of T2DM in Ukraine, which is most often used in accordance with the recommendations of the American Diabetes Association and the European Association for the Study of Diabetes ${ }^{19,20}$. According to the analysis of medical records of patients, metformin was received in the minimum dose that ensures the effectiveness and maximum tolerability of the medication, $1500-2000 \mathrm{mg} /$ day.

Combined therapy received by some patients included metformin and sulfonylurea derivative - gliclazide, the medication among the sulfonylurea the most commonly used in the treatment of T2DM due to its pricing policy ${ }^{21}$.

When evaluating the effectiveness of the received therapy, the target value of HbA1c less than $7 \%$ was highly thought, according to the recommendations of the ADA for glycemic control ${ }^{14,19}$.

The study results were analysed using STATISTICA 7.0 and MedCalc software. The Kolmogorov-Smirnov test was used to compare probability distributions. Quantitative values, because of their non-parametric distribution, are given in the form of median, lower, and upper quartiles, and compared using the Mann-Whitney test. For frequency values, the percentage ratio and its $95 \%$ confidence interval were calculated, and their comparative analysis was performed using Pearson's chi-square test and Fisher's bilateral test.

\section{Results}

The statistical analysis indicates the probability of differences between the study groups depending on the type of glucose-lowering therapy for T2DM patients and the influence on the choice of corrective therapy for comorbid pathology. Thus, majority of patients with T2DM, regardless of BMI and the presence of $\mathrm{CP}$, received combined therapy. The highest percentage of patients on combined therapy was recorded in the $\mathrm{T} 2 \mathrm{DM}+\mathrm{CP}$ group (Table 2).

When analysing the frequency of different types of glucose-lowering therapy for T2DM, depending on the presence or absence of comorbid CP, it was found that $81.45 \%$ of patients with T2DM + CP received combined therapy (metformin + sulfonylurea derivatives), which exceeded the number of patients on metformin monotherapy, as well as the number of patients with T2DM without CP (Table 3).

When analysing the frequency of different types of glucose-lowering therapy for T2DM, depending on the body mass index, it was found that patients with T2DM and normal body weight most often received combined therapy. The highest percentage of patients on combined therapy was recorded at T2DM with normal body weight (Table 4).

There was no significant difference between serum glucose and HbAlc levels in patients with only T2DM and comorbid T2DM with CP and overweight/obesity with monotherapy vs combined glucose-lowering therapy. However, glucose and $\mathrm{HbAlc}$ levels in patients with only T2DM on metformin monotherapy were significantly lower, respectively, by $41.72 \%$ and $25.64 \%$, compared to those in patients with comorbid T2DM with CP and overweight/obesity, who were also prescribed monotherapy (Table 5).

The obtained data indicate the influence of comorbidity on the choice of treatment for T2DM. Most of patients with T2DM+CP and T2DM with normal body weight received combined therapy (metformin + sulfonylurea derivatives).

Both the use of metformin as monotherapy and the use of combined therapy (metformin + gliclazide) in most of patients with only T2DM and comorbid T2DM with CP and overweight/obesity do not achieve the target levels of glucose and HbAlc (Table 6). 
Table 2. Characteristics of glucose-lowering therapy for T2DM patients

\begin{tabular}{ccccc}
\hline \multirow{2}{*}{ Groups } & \multicolumn{3}{c}{ Monotherapy (metformin) } & \multicolumn{2}{c}{ Combined therapy (metformin + gliclazide) } \\
\cline { 2 - 5 } & $n$ & $\%(95 \% \mathrm{CI})$ & $n$ & $\%(95 \% \mathrm{CI})$ \\
\hline Group 1 & 17 & $2.37(14.78 ; 40.62)$ & 50 & $74.63(55.39 ; 98.39)$ \\
\hline Group 2 & 4 & $12.50(3.41 ; 32.00)$ & 28 & $87.50(58.14 ; 100.00)$ \\
\hline Group 3 & 47 & $37.30(27.14 ; 49.60)$ & 79 & $62.70(49.64 ; 78.14)$ \\
\hline Group 4 & 6 & $18.18(6.67 ; 39.57)$ & 166 & $61.82(53.92 ; 100.00)$ \\
\hline Group 5 & 96 & $36.64(29.68 ; 44.75)$ & 46 & $77.97(57.08 ; 100.00)$ \\
\hline Group 6 & 13 & $22.03(11.73 ; 37.68)$ & $\chi^{2}=16.82 ; \mathrm{p}=0.005^{*}$ & \\
\hline$\chi^{2}$ Pearson's, p & & \multicolumn{3}{c}{}
\end{tabular}

Note. ${ }^{*}$ - statistically significant results.

Table 3. Characteristics of glucose-lowering therapy for T2DM patients depending on the presence or absence of chronic pancreatitis

\begin{tabular}{ccccc}
\hline Groups & \multicolumn{2}{c}{ Monotherapy (metformin) } & \multicolumn{2}{c}{ Combined therapy (metformin + gliclazide) } \\
\cline { 2 - 5 } & $n$ & $\%(95 \% \mathrm{CI})$ & $n$ & $\%(95 \% \mathrm{CI})$ \\
\hline $\begin{array}{c}\text { T2DM without CP } \\
\text { (Groups 1+3+5) }\end{array}$ & 160 & $\begin{array}{c}35.16 \\
(29.93 ; 41.06)\end{array}$ & 295 & $\begin{array}{c}64.84 \\
(57.65 ; 72.67)\end{array}$ \\
\hline $\begin{array}{c}\text { T2DM with CP } \\
\text { (Groups 2+4+6) }\end{array}$ & 23 & $\begin{array}{c}18.55 \\
(11.76 ; 27.83)\end{array}$ & 101 & $\begin{array}{c}81.45 \# \\
(66.34 ; 98.97)\end{array}$ \\
\hline $\mathrm{p}$ & & & $<0.001^{*}$ & \\
\hline
\end{tabular}

Note. ${ }^{*}$ - statistically significant results regarding the type of glucose-lowering therapy; $\#$ - statistically significant results regarding the presence or absence of $\mathrm{CP}$

Table 4. Characteristics of glucose-lowering therapy for T2DM patients depending on the presence or absence of overweight/obesity

\begin{tabular}{ccccc}
\hline \multirow{2}{*}{ Groups } & \multicolumn{2}{c}{ Monotherapy (metformin) } & \multicolumn{2}{c}{ Combined therapy (metformin + gliclazide) } \\
\cline { 2 - 5 } & $n$ & $\%(95 \% \mathrm{CI})$ & $n$ & $\%(95 \%$ CI) \\
\hline $\begin{array}{c}\text { T2DM patients with normal body } \\
\text { weight (Groups 1+2) }\end{array}$ & 21 & $\begin{array}{c}21.21 \\
(13.13 ; 32.42)\end{array}$ & 78 & $\begin{array}{c}78.79 \\
(62.28 ; 98.33)\end{array}$ \\
\hline $\begin{array}{c}\text { T2DM patients with overweight } \\
\text { (Groups 3+4) }\end{array}$ & 53 & $\begin{array}{c}33.33 \\
(24.97 ; 43.60)\end{array}$ & 106 & $\begin{array}{c}66.67 \\
(54.58 ; 80.63)\end{array}$ \\
\hline $\begin{array}{c}\text { T2DM patients with obesity (Groups } \\
\text { 5+6) }\end{array}$ & 109 & $\begin{array}{c}33.96 \\
(27.88 ; 40.96)\end{array}$ & 212 & $\begin{array}{c}66.04 \\
(57.45 ; 75.56)\end{array}$ \\
\hline$\chi^{2}$ Pearson's, $\mathrm{y}$ & $\chi^{2}=5.99 ; \mathrm{p}=0.05$ & \\
\hline
\end{tabular}

Table 5. Glycemic and HbA1c indicators of T2DM patients depending on the type of glucose-lowering therapy

\begin{tabular}{|c|c|c|}
\hline Indicators & $\begin{array}{c}\text { Monotherapy (metformin) } \\
(n=183)\end{array}$ & $\begin{array}{l}\text { Combined therapy (metformin }+ \text { gliclazide) } \\
(n=396)\end{array}$ \\
\hline & \multicolumn{2}{|c|}{ without comorbidity (Group 1) } \\
\hline & $\mathrm{n}=17$ & $n=50$ \\
\hline Glucose, $\mathrm{mmol} / \mathrm{L}$ & $7.67(5.90 ; 9.31)$ & $8.46(6.24 ; 10.32)$ \\
\hline \multirow[t]{3}{*}{$\mathrm{HbA} 1 \mathrm{c}, \%$} & $7.41(5.56 ; 8.50)$ & $7.68(6.41 ; 9.05)$ \\
\hline & \multicolumn{2}{|c|}{ with comorbidity (Groups $2+3+4+5+6$ ) } \\
\hline & $\mathrm{n}=166$ & $\mathrm{n}=346$ \\
\hline Glucose, $\mathrm{mmol} / \mathrm{L}$ & $10.87 \#(8.90 ; 13.31)$ & $9.70(7.80 ; 12.94)$ \\
\hline $\mathrm{HbA1c}, \%$ & $9.31 \#(8.30 ; 10.50)$ & $8.70(7.47 ; 10.00)$ \\
\hline
\end{tabular}

Note. There are no statistical differences depending on the type of glucose-lowering therapy ( $>0.05)$.

\# - statistically significant results regarding the presence or absence of comorbidity 
Archives of the Balkan Medical Union

Table 6. HbA1c levels of T2DM patients

\begin{tabular}{|c|c|c|c|c|}
\hline \multirow{3}{*}{ Groups } & \multicolumn{4}{|c|}{ Level of HbAlc } \\
\hline & \multicolumn{2}{|c|}{ Target $(<7 \%)$} & \multicolumn{2}{|c|}{$\operatorname{High}(>7 \%)$} \\
\hline & $n$ & $\%(95 \% \mathrm{CI})$ & $n$ & $\%(95 \% \mathrm{CI})$ \\
\hline & \multicolumn{4}{|c|}{ without comorbidity (Group 1) } \\
\hline Patients receiving metformin $(n=17)$ & 6 & $\begin{array}{c}35.29 \\
(31.29 ; 39.29) \\
\end{array}$ & 11 & $\begin{array}{c}64.71 \\
(59.98 ; 69.44) \\
\end{array}$ \\
\hline \multirow[t]{2}{*}{ Patients receiving combined therapy $(n=50)$} & 11 & $\begin{array}{c}22.00 \\
(17.27 ; 26.73)\end{array}$ & 39 & $\begin{array}{c}87.00 \\
(81.35 ; 92.65)\end{array}$ \\
\hline & \multicolumn{4}{|c|}{ with comorbidity (Groups $2+3+4+5+6)$} \\
\hline Patients receiving metformin $(n=166)$ & 27 & $\begin{array}{c}16.27 \\
(10.72 ; 22.47)\end{array}$ & 156 & $\begin{array}{c}83.73 \\
(71.69 ; 99.92) \\
\end{array}$ \\
\hline Patients receiving combined therapy $(n=346)$ & 65 & $\begin{array}{c}17.79 \\
(12.67 ; 20.92)\end{array}$ & 331 & $\begin{array}{c}82.21 \\
(73.82 ; 92.09)\end{array}$ \\
\hline Fisher's criterion, $\mathrm{p}$ & \multicolumn{4}{|c|}{$\mathrm{p}>0.05$} \\
\hline
\end{tabular}

\section{Discussion}

The development of T2DM is based on relative insulin insufficiency which, in turn, occurs when the patient has two combined pathophysiological disorders - decreased sensitivity of peripheral tissues to insulin (insulin resistance (IR)) and deterioration of the insular apparatus of pancreatic $\beta$-cells. The activity and contribution of each of these two mechanisms to the etiology and pathogenesis of T2DM are different, regardless of the presence or absence of obesity $y^{22,23}$. It should be emphasized that T2DM is a progressive metabolic disease in which carbohydrate metabolism is deteriorated over time (due to the so-called phenomenon of "glucose intoxication" $)^{24,25}$. Therefore, appropriate glucose-lowering therapy allows not only to reduce glycemia, to achieve compensation for diabetes, to eliminate the clinical manifestations of the disease, but also to break the "vicious circle" caused by the phenomenon of "glucose toxicity".

For the treatment of T2DM, eight groups of glucose-lowering tablets are currently used - oral glucose-lowering agents ${ }^{26}$. However, according to various sources, $30-50 \%$ of patients diagnosed with T2DM receive insulin therapy ${ }^{14,19}$. According to the UK Prospective Diabetes Study (UKPDS), a landmark randomized multicenter trial of glycemic therapies in 5,102 patients with newly diagnosed T2DM, already at the stage of initial diagnosis, $5-10 \%$ of patients need constant insulin therapy, and after 10-12 years this indicator is already reaching $80 \%{ }^{27}$. Most often, modern tactics of T2DM treatment, which involves the correction of chronic hyperglycemia by overcoming IR and improving $\beta$-cell function of the pancreas, are to prescribe a combination of biguanides and sulfonylureas $^{28}$. Metformin belongs to biguanides, it inhibits the formation of glucose in the liver and reduces fasting glycemia, increases hepatic and peripheral insulin sensitivity (but does not affect its secretion), influences on insulin receptors. Thus, the effect of metformin helps to reduce IR at various levels: in the liver, skeletal muscle and adipose tissue. Metformin slows down the absorption of carbohydrates in the intestine, enhances glucose utilization by the cells of the intestinal mucosa and smooths glycemic peaks after eating ${ }^{29}$.

In addition, metformin has anorexigenic effect. The drug slows down the development of T2DM, promotes weight loss and has a protective cardiovascular effect, improves lipid metabolism, with a decrease of FFAs levels, LDL-C and VLDL-C, an increase of HDL-C levels, inhibition of oxidative stress, improvement of vascular relaxation and a decrease of the proliferation of smooth muscle cells ${ }^{29}$. Thus, metformin is well tolerated, is not associated with hypoglycemia, promotes weight loss and is safe in the short- and long-term perspective; it may provide a protective effect against cardiovascular disease and certain types of cancer $^{30}$.

Sulfonylurea derivatives are considered first-line glucose-lowering drugs if the patient has a normal body weight, postprandial hyperglycemia predominates, moderate insulin deficiency is present, intolerance or contraindication to the use of metformin is determined, if rapid glycemic control is required. They are also recommended for combined oral therapy. Sulfonylurea derivatives stimulate insulin secretion by closing of ATP-sensitive potassium channels and, consequently, opening calcium channels. The accumulation of calcium in the cell triggers the process of insulin secretion ${ }^{31}$.

T2DM is a disease that associates many comorbidities. On one hand, diabetes itself contributes to the development of comorbidities, and on the other hand, comorbidities have a serious impact on its course, treatment tactics and clinical outcomes ${ }^{32-34}$. 
The strategy for the treatment of comorbid diseases is the pathogenetic therapy and a personalized approach. These are the factors that determine the choice of the medication. Our analysis shows the influence of comorbid CP on the choice of treatment tactics for T2DM, particularly, $81.5 \%$ of patients with T2DM in combination with CP were prescribed combined therapy (metformin + gliclazide), while overweight/obesity is not a criterion for choosing monoor combined glucose-lowering therapy.

For a long time, there has been a discussion about how CP and DM are related. In the case of their development in the same patient, should they be considered as two independent diseases, or one of them is a natural consequence of the other? Most studies of pancreatic exocrine function in diabetic patients have reported mild and moderate exocrine pancreatic insufficiency, which has been expressed in a relative decrease of bicarbonate and enzyme production, and severe pancreatic exocrine insufficiency with steatorrhea is relatively rare ${ }^{35-37}$. According to Sirchak et al, in patients with T2DM, CP is formed on the background of biliary pathology, while the functional capacity of the pancreas is greater than in $\mathrm{T}_{1 \mathrm{DM}}{ }^{38}$. There was an inverse correlation of the fecal elastase level with the duration of diabetes and the content of HbAlc, and a direct correlation with the concentration of C-peptide in the group of patients with T2DM ${ }^{39,40}$. In T2DM, the synthesis of amylase and trypsin is disrupted in $15-73 \%$ of cases, and there is a feedback of the activity of pancreatic enzymes with postprandial glycemia ${ }^{41}$.

Several mechanisms of the development of exocrine pancreatic insufficiency in DM have been suggested $^{41-45}$ : insulin deficiency, leading to a decrease of pancreatic trophism, contributes to its atrophy; insulin deficiency reduces the secretion of pancreatic enzymes, in particular, there is a positive correlation between the residual $\beta$-cell function and the concentration of fecal elastase-1; change in incretion or imbalance of insulin and other islet hormones (glucagon, somatostatin, pancreatic polypeptide); autoimmune processes common to diabetes and CP: several studies in Japan have shown the presence of antibodies to various antigens of the exocrine pancreas at T1DM, for example, antibodies to pancreatic cytokeratin were detected in 39\%, antibodies to lipase in $73.5 \%$ and antibodies to lactoferrin or carbonic anhydrase in $77 \%$ of all patients; diabetic angiopathy, presumably contributing to the development of pancreatic fibrosis; diabetic neuropathy and impairment of enteropancreatic reflexes.

The assessment of the comorbidity level in patients with T2DM can be clinically significant in predicting the achievement of individual treatment goals of a particular patient and in predicting the development of insulin demand. There was no significant difference between glucose and $\mathrm{HbAlc}$ levels in patients with only T2DM and comorbid T2DM with $\mathrm{CP}$ and overweight/obesity with glucose-lowering monotherapy vs combined therapy. However, glucose and $\mathrm{HbAlc}$ levels in patients with only T2DM on metformin monotherapy were significantly lower than in patients with comorbid T2DM with CP and overweight/obesity who were also prescribed monotherapy. However, in patients who were receiving combined therapy, there was no significant difference between glucose and HbAlc levels in case of only T2DM and comorbid T2DM with CP and overweight/obesity.

In this case, the level of comorbidity is an important criterion to be considered when determining target glycemic values. Predicting the effectiveness of treatment and medical rehabilitation of patients with T2DM allows for a personalized approach to diagnosis and treatment ${ }^{33}$. Our analysis shows that both the use of metformin as monotherapy and the use of combined therapy (metformin + gliclazide) in the vast majority of patients with only T2DM and comorbid T2DM with CP and overweight/obesity does not achieve the target levels of glucose and HbA1c. The obtained data raise concerns, because of the well-known importance of glycemic control in patients with comorbid pathology $y^{32}$. Tian et al. also note that long-term maintenance of the target HbA1c level in patients with coronary heart disease and DM reduces the incidence of coronary restenosis and improves the prognosis after percutaneous coronary intervention, and hyperglycemia that precedes stroke aggravates its course and increases the percentage of deaths. Moreover, hyperglycemia control for a relatively short time, preceding the stroke, does not reduce its risk and does not improve the prognosis ${ }^{46}$.

\section{Conclusions}

It becomes increasingly important to demonstrate the differentiated approach to the glucose-lowering therapy in T2DM patients depending on comorbidities. According to our study, the presence of $\mathrm{CP}$ significantly affects the choice of treatment for T2DM, in special combination therapy (metformin + sulfonylurea derivatives), while overweight/obesity is not a criterion for choosing mono- or combined glucose-lowering therapy.

It is important to note that both the use of metformin as monotherapy and the use of combined therapy (metformin + gliclazide) in most of patients with only T2DM and comorbid T2DM with CP and overweight/obesity do not achieve the target levels of 
serum glucose and HbA1c. Clinicians should focus on target-oriented nature of diabetes treatment and its effectiveness in individual patients.

\section{Author Contributions:}

Conceptualization, M.M.; methodology, U.H., S.D.; software, L.M., Y.D.; validation, U.H.; formal analysis, U.H., S.D.; investigation, U.H; resources, I.K., Y.D.; data curation, U.H.; writing original draft preparation, U.H., Y.D., S.D.; writing review and editing, I.K., M.M. L.M.; visualization, I.K.; supervision, M.M. All the authors have read and agreed with the final version of the article.

\section{Compliance with Ethics Requirements:}

"The authors declare no conflict of interest regarding this article"

"The ethical principles included in the Declaration of Human Rights adopted in Helsinki, in 1975, and revised in 2008, were fully respected in our study. The enrolled subjects participated in this study voluntarily, completed and signed a written informed consent. Study protocol was approved by the Ethics Committee of I. Horbachevsky Ternopil National Medical University"

\section{Acknowledgments}

"The research was supported and funded by the Ministry of Health of Ukraine"

\section{References}

1. Talukder A, Hossain Z. Prevalence of diabetes mellitus and its associated factors in bangladesh: application of two level logistic regression Model Scientific Reports. 2020;10:10237.

2. International Diabetes Federation. IDF Diabetes Atlas. 9th edition Brussels (BEL). IDF. 2019. https://www.diabetesatlas.org/en/

3. Nowakowska M, Zghebi SS, Ashcroft DM, et al. The comorbidity burden of type 2 diabetes mellitus: patterns, clusters and predictions from a large English primary care cohort. BMC Med. 2019; 17, 145. https://doi.org/10.1186/ s12916-019-1373-y

4. Marushchak M, Krynytska I, Milevska L, Miz A, Mialiuk O. The changes of activity of effector caspase cascade components in case of alimentary obesity in rats. Bangladesh Journal of Medical Science. 2017;16(2):252-258.

5. Yarema N, Kotsiuba O, Krytskyy T, Marushchak M, Krynytska, I. Peculiarities of arterial hypertension in postmenopausal women with bone mineral density disorders and dyslipidemia. Polski Merkuriusz Lekarski. 2020;48(283):5-9.

6. Blüher M, Stumvoll M. Diabetes and Obesity. Diabetes Complications, Comorbidities and Related Disorders. Endocrinology. Springer, Cham. 2018. https://doi. org/10.1007/978-3-319-44433-8_1

7. Leon BM, Maddox TM. Diabetes and cardiovascular disease: Epidemiology, biological mechanisms, treatment recommendations and future research. World J Diabetes. 2015;6(13):1246-1258.
8. Mooradian AD, Albert SG, Haas MJ. Low serum high-density lipoprotein cholesterol in obese subjects with normal serum triglycerides: the role of insulin resistance and inflammatory cytokines. Diabetes Obes Metab. 2007;9:441-443.

9. Hamilton SJ, Watts GF. Endothelial dysfunction in diabetes: pathogenesis, significance, and treatment. Rev Diabet Stud. 2013;10:133-156.

10. Marushchak M, Maksiv K, Krynytska I. ACE gene I/D polymorphism and arterial hypertension in patients with COPD. Pneumologia. 2019;68:1-6.

11. Zhuravleva LV, Shekhovtsova YuA. Comorbidity of chronic pancreatitis and diabetes type 2: possible options of pharmacoteraphy. Practical Doctor. 2016;5(3):21-25.

12. American Diabetes Association. Comprehensive medical evaluation and assessment of comorbidities: standards of medical care in diabetes. Diabetes Care. 2018;41(1):28-37.

13. Thrasher J. Pharmacologic management of type 2 diabetes mellitus: available therapies. The American Journal of Cardiology. 2017;130(6S):S4-S17.

14. American Diabetes Association. Standards of medical care in diabetes - 2019 abridged for primary care providers. Clin Diabetes. 2019;37(1):11-34.

15. Akram M. Diabetes mellitus type II: treatment strategies and options: a review. J Diabetes Metab. 2013;4:9.

16. Farah J, Wilk A, Nguyen N, Vasey J, Kallenbach L. Type 2 diabetes and management of cardiovascular and renal comorbidities: a cohort analysis with case study using electronic health records. Available from: https://veradigm.com/veradigm-news/type-2-diabetes-comorbidities-cohort-analysis/

17. Petznick A. Insulin management of type 2 diabetes mellitus. Am Fam Physician. 2011;84(2):183-190.

18. Conwell DL, Lee LS, Yadav D, et al. American Pancreatic Association Practice Guidelines in Chronic Pancreatitis: evidence-based report on diagnostic guidelines. Pancreas. 2014;43(8):1143-1162.

19. Davies MJ, D’Alessio DA., Fradkin J. Management of hyperglycemia in type 2 diabetes, 2018. A consensus report by the American Diabetes Association (ADA) and the European Association for the Study of Diabetes (EASD). Diabetologia. 2018;61:2461-2498.

20. Unified clinical protocol of primary and secondary (specialized) medical care type 2 diabetes mellitus. 2012. https://dec.gov.ua/wp-content/uploads/images/dodatki/ 2012_1118/2012_1118YKPMD.pdf

21. Tronko ND, Efimov AS, Tkach SN. Oral hypoglycemic drugs and tactics of their use. Kyiv. 2002:110.

22. Gaman MA, Epingeac ME, Diaconu CC, Gaman AM. Evaluation of oxidative stress levels in obesity and diabetes by the free oxygen radical test and free oxygen radical defence assays and correlations with anthropometric and laboratory parameters. World Journal of Diabetes. 2020;11(5):193-201.

23. Diaconu C, Nastasa A, Zaki AR, Arsalan M. Type 2 diabetes: a driver for chronic heart failure. The $2^{\text {nd }}$ International Conference on Interdisciplinary Management of Diabetes Mellitus and its Complications - Diabetes mellitus as cardiovascular disease, INTERDIAB 2016 Proceedings, pp. 201-210. Ed. Niculescu. Editors Serafinceanu C, Negoita O, Elian V.

24. Vlasenko MV, Kuchevska NV, Krivov'yaz YuO, Secret TV. Metformin in type 2 diabetes mellitus: in focus, respect key aspects. Practical Doctor. 2016;5(3):26-30.

25. Marushchak M, Lisnyanska N, Krynytska I, Chornomudz I. The mechanisms of apoptosis initiation in rats with chronic enterocolitis combined with streptozotocin-induced diabetes. Georgian Medical News. 2017;9(270):121-126. 
26. Kurnikova IA, Ualikhanova AU, Meleshkevich TA, Kiryanova LV. Quality of glycemic control in estimating the formation of insulin needs in patients with comorbid pathology on the backround of type 2 diabetes mellitus. Diabetes. 2018;21(2):118-127.

27. UK Prospective Diabetes Study (UKPDS) Group. Intensive blood-glucose control with sulphonylureas or insulin compared with conventional treatment and risk of complications in patients with type 2diabetes (UKPDS 33). Lancet. 1998;352:837-853.

28. Ametov AS, Pakus EN. Efficacy and safety of metformin-sitagliptin combination for the treatment of patients with diabetes mellitus and obesity. Diabetes Mellitus. 2010;3:62-64.

29. Zhuravleva LV, Shekhovtsova YuA. Comorbidity of chronic pancreatitis and diabetes type 2: possible options of pharmacotherapy. Practical Doctor. 2016;5(3):21-25.

30. Starting Metformin GP and practice nurse guide to patient information Leaflet. Metformin GP information leaflet. 2018. Available from: https://hertsvalleysccg.nhs.uk/application/files/8315/3633/4454/Metformin_GP_information_leaflet_v1.0_April_2018.pdf

31. Novytska AV. You are on the way to prophylaxis and treatment of children with type 2 diabetics on the first line of primary care for medical assistance, especially drug therapy. Medicine of Ukraine. 2016;3(199):60-70.

32. Vasiltseva OYa, Vorozhtsova IN. The importance of glycemic control in patients with comorbid pathology. Consilium Medicum. 2018;20(10):96-100.

33. Kurnikova IA, Akhmadullina GI, Zykina SA. The level of comorbidity and the effectiveness of medical rehabilitation of patients with type 2 diabetes. Bulletin of Neurology, Psychiatry and Neurosurgery. 2016;12:10-16.

34. Munteanu MA, Gheorghe G, Stanescu AMA, et al. Chronic heart failure and diabetes mellitus: two unsuitable matched partners. Arch Balk Med Union. 2020;55(1):128-133.

35. Hardt PD, Hauenschild A, Nalop J, et al. High prevalence of exocrine pancreatic insufficiency in diabetes mellitus. A multicenter study screening fecal elastase 1 concentrations in 1,021 diabetic patients. Pancreatology. 2003;3(5):395-402.
36. Mogoanta SS, Costache A, Mutiu G, et al. A nonfunctional neuroendocrine tumor of the pancreas - a case report. Rom J Morphol Embriol. 2015;56(2 Suppl.):511-519.

37. Gheorghe G, Bungau S, Ilie M, et al. Early diagnosis of pancreatic cancer: the key for survival. Diagnostics. 2020;10: 869 .

38. Sirchak NS, Barani VY, Fabri ZY. Specifications of peculiarities of external secretorial failure of the pancreas in patients with diabetes mellitus and chronic pancreatitis. Problems of Clinical Pediatrics. 2020;1-2(47-48):53-59.

39. Ewald N, Raspe A, Kaufmann C, Bretzel RG, Kloer HU, Hardt PD. Determinants of exocrine pancreatic function as measured by fecal elastase-1 concentrations (FEC) in patients with diabetes mellitus. Eur J Med Res. 2009;14(3):118-122.

40. Terzin V, Várkonyi T, Szabolcs A, et al. Prevalence of exocrine pancreatic insufficiency in type 2 diabetes mellitus with poor glycemic control. Pancreatology. 2014;14(5):356-360.

41. Gubergrits NB, Fomenko PG, Kolkina VYa. Exocrine pancreatic insufficiency at diabetes mellitus. Russian Journal of Gastroenterology, Hepatology, Coloproctology. 2009;19(5):61-67.

42. Lomakina EYu, Taratina OV, Belousova EA. Chronic pancreatitis and diabetes mellitus: a literature review. Almanac of Clinical Medicine. 2019;47(6):525-534.

43. Young AA, Cooper GJ, Carlo P, Rink TJ, Wang MW. Response to intravenous injections of amylin and glucagon in fasted, fed, and hypoglycemic rats. Am J Physiol. 1993;264(1):943-950.

44. Taniguchi T, Okazaki K, Okamoto M, et al. High prevalence of autoantibodies against carbonic anhydrase II and lactoferrin in type 1 diabetes: concept of autoimmune exocrinopathy and endocrinopathy of the pancreas. Pancreas. 2003;27(1):23-26.

45. Chakraborty PP, Chowdhury S. A look inside the pancreas: the "Endocrine-Exocrine Crosstalk". Endocrinol Metab Synd. 2015;4(1):160.

46. Tian F, Chen Y, Liu H. Assessment of characteristics of neointimal hyperplasia after drug-eluting stent implantation in patients with diabetes mellitus: an optical coherence tomography analysis. Cardiology. 2014;128(1):34-40. 